\title{
ADVANTAGES AND DISADVANTAGES OF ADVERTISING BY SOCIAL NETWORKS
}

\author{
Nataša Simić, ${ }^{1}$ Vesna Petrović, ${ }^{2}$ Dušan Aničić, ${ }^{3}$ \\ ${ }^{1,2,3}$ University UNION Nikola Tesla, Faculty of Economy, Belgrade, Republic of Serbia \\ nsimic68@gmail.com, al.petrovicpn@gmail.com, anicic.dusan@yahoo.com
}

\section{Professional Paper doi:10.5937/jouproman7-21994}

\begin{abstract}
Global technological progress has significantly affected public relations. New communication technologies have enabled creation of competent markets. Development of modern technology affected the production of the so-called personal products which have been created based on knowledge of consumer demands and needs. Pursuant to that, the communication is based on two-sidedness, and the central point of interactive public relations is taken by communication model "one on one" and "many to many", instead of the communication model which is directed toward masses, where the dominant direction is "one to many".

There is a high degree of consent on the role and significance of social networks at all levels, starting from the global corporate success to resolution of daily problems of individuals. One of the most important problems is the safety of companies' appearance in the cyber space. This paper is supposed to point out to the advantages, as well as dangers with which companies face when conquering their "piece" of cyber space.
\end{abstract}

Key words: cyber space, social networks, internet marketing, advertising

\section{INTRODUCTION}

The modern business of today is almost entirely dependent on information technology and data processing methods. The impact of informatics leads to the creation and development of new industries that direct human activities and concentrate knowledge on information processing operations. ${ }^{17}$ Today, entrepreneurial work can not be imagined without the internet, whereby an

17 Filipovic,V.,Kostic, $\quad$ M.,: $\quad$ Marketing Management - Theory and Practice, Faculty of Organizational Sciences, Belgrade.2003. entrepreneur can perform a large number of activities in a very simple way, quickly and regardless of time and geographical distance. Non existence (non appearance) on the Internet today puts into question not only success, but also the survival of the company.

\section{THE IMPORTANCE OF INTERNET MARKETING IN ENTREPRENEURSHIP}

Internet marketing is a common denominator for all types of online marketing (e-marketing, cyber marketing, internet marketing and web marketing). It implies all marketing activities that use the Internet (web and e-mail) as a channel of marketing communication.

Internet marketing relies heavily on the stages of the traditional marketing process: ${ }^{18}$

- situational analysis,

- marketing planning,

- implementation.

Internet marketing relies heavily on databases. It implies careful and precise use of information about current and potential customers, competition and internal company information stored in a computer database with a focus on marketing activities targeted at target markets.

${ }^{18}$ Reedy, J., Schullo, S. Zimmerman, K. (2000): Electronic Marketing- Integrating Electronic Resources into Marketing Process, The Dryden Press, Harcourt College Publishers, Orlando, FL. 
The Internet has many advantages over other conventional advertising media. They are primarily reflected in comprehensiveness and applicability, unlike other media and communication channels. Consumables, as well as clients can get information, pay and buy online. In addition, there is also interactivity of the Internet, where consumers, customers and others initiate the process of purchasing visits to the website. It should also be noted the measurability of the effects of Internet advertising. The effectiveness of internet promotion is measurable, because it can accurately determine how many times the ads are viewed and how many times the visitors went through it to the website. Multimedia character of the Internet is unique. This is very important from the aspect of advertising. The Internet can transfer not only text and graphics, but also video and audio content. Thus, the Internet becomes an integral part of the promotional mix for many advertisers, and therefore new forms and shapes appear: animated banners, 3D animations, etc.

Internet networking can be twofold: business and social. Business on-line networking is used to connect companies with other companies such as suppliers, sales networks, etc. Social networking is based on communication in a form of conversation (two-way) between people where key values are sincerity and transparency. Marketing activities used on online networks are similar to those used on the web site:

Banner advertising (banner is a space of a certain size on a website that is rented in a certain period and leads to the desired web site. Banner can include video, audio and interactive content). It is most often paid "per click".

E-mail campaigns: Sending targeted e-mail to a specific group of clients or potential clients with special offers, discounts and other promotional information.
Viral marketing: Campaigns that "provoke" referrals by creating the conditions for users to simply download the desired message to their network of contacts. The simple method is to create content for Youtube in the form of video and audio material.

Link building: some social networks provide a profile page, blogs or pages that users can edit, which are linked to company websites.

\section{CONCEPT OF SOCIAL NETWORKS}

With the development of the Internet, social networks have developed, as well as free online services that enable communication and connection of users. The first modern social network was SixDegrees, and was launched in 1997. The site provided the ability to create profiles and make friends, but it is no longer functional today. Social networks (Facebook, Twitter, Google Plus +, Youtube, etc.) are now used by hundreds of millions of people.

The benefits of marketing through social networks are relatively low campaign costs, fast feedback, increased traffic to the website, brand enhancement, easy and quick launch of new products or services. ${ }^{19}$ It's often considered that members of social networks are younger people who use Facebook, to share statuses and photos and open Facebook groups. With the advent of new media, different types of specialized social virtual networks have been identified to establish virtual friendships, entertainment, learning, marketing and sharing knowledge and information.

The specific feature of social networks is the freedom and ease of accessing networks based on the selection of a specific network depending on the needs and interests. However, recently, members of social networks become business people who open their company's pages on social networks.

19 Bauer, I.: Digital Marketing, Institute for Textbooks, Belgrade, 2013. 
The term social network has been in existence for more than half a century, but with the development of a social networking site such as Facebook, Twitter, Linkedin and others, it has transformed the old term into one of the most important and used internet concepts for many years. Social networks make invisible social connections, visible in a way to spot who our friends are, who are their friends, etc.

\section{HISTORY OF SOCIAL NETWORK DEVELOPMENTS}

It can be said that the history of the development of social networks coincides with the development of the Internet as a network of all networks that enables the functioning of another life. The first period (1980-2002) is characterized by the appearance of prototypes of social networks that we know today as Facebook, Myspace and others. So in 1995, Classmates.com and Match.com appeared, and in 1999 Blackplanet.com, MiGente.com and AsianAvenue.com. The real rise of social networks is created after 2002. In 2003, the social network MySpace was founded, which until Facebook was the most popular and dominant, and in 2006 the LinkedIn business network appeared.

Today are the most influential Facebook and Twitter. Over time, various profiles or types of social networks were formed. It is a process of personalization and specialization according to the needs and interests of the users. Users are grouped precisely according to the criteria of needs, interests and social roles as well as social status.

\section{FACEBOOK}

In 2004, Facebook was launched by Mark Zuckerberg in order to connect Harvard students. Today, Facebook is the largest social network, but also an excellent advertising platform. It has more than 900 million active users, and is thus the most popular place to connect with other people and share information. Facebook was originally conceived as a Harvard social networking network for students to share information among themselves. Pages Facebook (formerly thefacebook.com) was launched in 2004, and soon afterwards expanded to other faculties, then secondary schools, private firms, and soon became publicly available for anyone to apply. In 2008, Facebook became the most popular Social Networking Web site, where 725 million users visit at the daily level, and it has passed the popular MySpace, and its growth continues. ${ }^{20}$ Today, any more serious company has a built-up Facebook page of its company and publishes quality content on it. Facebook also offers the possibility of Facebook Ads, a service that sends a message just to the part of the audience that may be interested in the services, or the company can use the Facebook Ads campaign to direct communication only to precisely selected groups of users selected by location, language, gender, age, interests, education and other important characteristics.

\section{TWITTER}

Twitter was created in 2006. Twitter is a popular social networking and microblogging service based on public posting and receiving short text messages up to 140 characters, the so-called tweets. Registered users can publish tweets, while unregistered users can only read them. Users show interest in a kind of subscription or tracking of other users and thus become their followers. Namely, using Twitter and publishing tweets can attract people to the company's website, promote new products or business results. By using hashtag (\#), events and campaigns can be promoted, and that all leads to the strengthening of the brand.

20 Marco Toledo Bastos: Journalism Studies, United Kingdom, 2014. 
Twitter can be used for advertising in a variety of ways, and a large number of people can easily join.

\section{PINTEREST}

Pinterest is a web service where images and video clips are stored and sorted. A relatively new social network based on the simplified idea that the image is worth more than a thousand words. This social network allows users to publish or display favorite pictures and videos to other users. In order to take advantage of the Pinterest, you need to make a quality profile on Pinterest and put pins (images, video clips) into plates with precise titles.

\section{GOOGLE PLUS+}

Google Plus is a social networking and identity detection service from Google d.d. This social network was launched on June 28, 2011 in the test phase, but could only be accessed via an invitation received from an e-mail. On October 20, 2011, Google allowed anyone over 18 to join this social network, while for the under 18, it was opened on January 26, 2012. This social network also allows the sharing of photos, videos, links and locations with friends, but only with a certain set of people. Google Plus has so-called circles and then users just create their own circles, such as family, work, friends, and accordingly, certain content is sent to certain circles.

\section{BENEFITS OF SOCIAL NETWORKS}

One of the main advantages of social networks is the sense of belonging, which allows users to chat and comment on photos by gaining a sense of belonging. Also, social networks are free and easy to access, which makes it easy to connect and make new friendships. Through social networks, information or news can be easily obtained, connecting people with the same interests and giving them the opportunity to discuss and share data. The next advantage is speed and mobility, which means that private messages and comments are transmitted within a few seconds, a problem can be solved more quickly. Private messages achieve deeper relationships and communication over a longer period of time, and all the information received can be used to improve the service or product.

\section{DISADVANTAGES OF SOCIAL NETWORKS}

As there are advantages of social networks, there are also shortcomings. All social networks are free and registration requires a corresponding e-mail address and username. For this reason, you need to be on the alert because you never know who is really hiding behind another user profile. In one survey of online behavior, this was also said: even $38 \%$ of social network users, such as Facebook or Twitter, announced in their status messages that they were on vacation, and $33 \%$ said they would spend the weekend out of their house. Knowing that a large number of 'friends' on social networks do not really know the users at all, there is an alarming fact that your home is exposed to a potential burglary. The study also showed that in $17 \%$ of the respondents, home addresses were clearly visible. Other shortcomings of social networks include: disclosure, loss of privacy, manipulation of private data for marketing purposes, anonymity and virtual identity, virtual friends, etc.

Disclosure is an individual, free process of giving information about oneself, which can be systematized and used for marketing and intelligence purposes or criminal purposes. In this procedure, individuals often provide all the information that others can use to control the disclosed person. By giving away their own data, they create a personal psychosocial profile of the user of the network, revealing hobbies, habits, social, sexual and political orientation. 
People can thus be controlled and used for different purposes. The main objection is the loss of privacy. Data on Facebook is not the property of an unveiled person, but Facebooks. Accordingly, Facebook contains billions of data that have a certain value and almost all rights are retained by the portal owner. Manipulating private data for marketing purposes is a moment when the freedom of self-discovery has its peak, benefits from various private data. In the information society, marketing companies that deal with global marketing can benefit. ${ }^{21}$ Social networking sites such as Facebook, Twitter, LinkedIn or other similar networks send data from their members to large marketing companies, despite the fact that on their site they claim that all the information that members leave are completely safe and secure. Inclusion in another world gives the possibility of escaping responsibility from the real social world in which living people meet. ${ }^{22}$ The second life or its construction, represent the technological possibility and potential of the escape from social reality because of fear or escape from life. The background or fuel of a second life is actually a growing disappointment with the real world, and an increasing alienation that then results in the escape of freedom.

Modern information and communication technology is also a medium that generates loneliness and isolation. It creates a fiction of belonging to large social networks where a person feels like a member of a virtual community, and at the same time becomes isolated from the real world. The phenomenon of alienation reached the peak with the emergence of information and communication technologies and new media that enabled the globalization of aliens. New social networks, therefore, are not at all social, but they are dotted with an

21 Nielsen Global AdView: Global advertising trends, 2012.

${ }^{22}$ Krum, C. : Mobile Marketing- Finding Your Customers No Matter Wherw They Are, Pearon Education, Indianapolis. 2010. alienated social network. There is also the dependence on social networks, where users retreat from the real world and strive to show the best in the virtual world. Children are always at risk by pedophiles, who are falsely represented and are trying to contact the children.

\section{ADVANTAGES OF ADVERTISING ON SOCIAL NETWORKS}

The benefits of advertising through social networks are: a monologue typical of television, radio and print. The campaign becomes transparent and we receive feedback from consumers, which are important for further strategic steps; Social networks do not have a time limit; any advancement of social networks enables even better communication and interaction between the brand and the consumer; social networks are the only communication channel where direct communication between the brand and the consumer can be achieved; Advertising prices on social networks are considerably less than the traditional way of advertising; you can get feedback about products or services; greater availability to consumers; increasing reputation and credibility; successful launch of new products or services.

\section{SAFETY ON SOCIAL NETWORKS}

Social networks have become an integral part of our lives on the Internet. It is necessary to observe how much personal information we publish on the Internet. Well, millions of people like us do this daily on extremely popular social networks. Nowadays, our mood on the Internet has a direct impact on the rest of our lives. Therefore, safety should be kept in mind. In this way, we protect our computer, money and reputation, as well as family and friends. 


\section{RISKS AND THREATS ON SOCIAL NETWORKS}

Social network risks relate to cybercrime that includes the sale of private data, identity theft, cyber spying, or the collection of information about someone through social networks, as well as various forms of political, religious, cultural and ethnic extremism, or the spread of hatred. Free access to social networks, relatively inexpensive technology gives the opportunity to work smoothly to various criminal, spy and extremist, pedophile groups. Governments and states do not stand aside when it comes to insurance against cybercrime and extremist networking. There are more and more norms in the field of rights related to an attempt to regulate behavior on social networks. This type of regulation aims not to control social networks, but rather to protect the integrity of people, social groups, especially children from inappropriate or extremist action. Security threats that weigh on social networks can be divided into four groups: privacy threats, threats to networks and data, identity threats, and social threats. Privacy Threats - Users register their personal information when registering on a social network and are deliberately disclaiming their privacy. Threats to privacy include the collection of digital user records, the collection of secondary data, the identification of the face of the user, the detection of data using photos, the linking of data and tags in photographs, inability to completely delete the user account. Threats to networks and data that are current on social networks: Spam on Cross site scripting (XSS), viruses and worms on Multi-Social Profiler Tools (Snag, ProfileLinker). Threats to identity - threats to identity can be: Phishing attacks (identity theft, damage to the reputation of the user), data disclosure, false profiles. Social threats can be: citing, cyber violence, industrial espionage (loss of intellectual property, attack on the company's computer infrastructure, blackmail of employees in the company, access to material assets of an individual or company).

\section{HOW TO PROTECT YOURSELF?}

To protect yourself against malicious attacks on user data on social networks, you need to pay attention to the following steps: the Internet is a public resource, which means that the user should not display on his profile what he does not want to see a wide circle of people, because when Once on the Internet, they can not be deleted. Everything remains on social networks even though the profile is deleted. Do not give user accounts and passwords when communicating with foreigners. The use of strong passwords is important because it is the first step in securing a user account, limiting the amount of personal information that is displayed on the social network (where the user can decide which information to reveal on a social network about himself). When registering on a social network, it is advisable for the user to become familiar with the rules and privacy policy of a particular network.

\section{CONCLUSION}

The very fact that in a short period of time the product or service being advertised will be seen by several thousand people, that according to the analyst there is a possibility to know where these people are, to indicate them to apply to the notifications list, and along with the implementation of the orders, give maximum return on investment. In the last century, one of the basic Web slogans was: "If you do not exist on the Internet, you do not exist." The slogan that would be worthwhile today might come from it, and he would say: "Unless you are recognizable on the Internet, you do not exist." 
Each type of advertising has its advantages and disadvantages, as well as its specific price, and the company depends on how much it wants to invest in advertising to promote the product or service. Advertising on social networks is being used increasingly because it is the cheapest and most effective way of advertising. We live in the age of a global information society, where the backbone of this society is made up of new informationcommunication technologies, the Internet and new media. Without these technologies, modern reality could hardly be understood.

\section{REFERENCES}

[1] Bauer, I.: Digital Marketing, Institute for Textbooks, Belgrade, 2013.

[2] Filipovic,V., Kostic, M.,: Marketing Management - Theory and Practice, Faculty of Organizational Sciences, Belgrade.2003.

[3] Krum, C.: Mobile Marketing- Finding Your Customers No Matter Wherw They Are, Pearon Education, Indianapolis. 2010.

[4] Marco Toledo Bastos: Journalism Studies, United Kingdom, 2014.

[5] Nielsen Global AdView: Global advertising trends, 2012.

[6] Reedy, J., Schullo, S. Zimmerman, K.: Electronic Marketing- Integrating Electronic Resources into Marketing Process, The Dryden Press, Harcourt College Publishers, Orlando, FL. 2000. 